\section{High Impact Extension Programming with Instagram}

\author{
Melanie Stock ${ }^{1}$
}

ADDITIONAL INDEX wORDs. agriculture, follower, horticulture, influencer, social media, urban farm

SUMMARY. The social media service Instagram is a popular public platform, but often underused tool to reach new demographics, reduce barriers, and perpetuate sciencebased information in extension. In the U.S. Intermountain West, Instagram was the top-rated platform for sharing information by predominantly new and female farmers. This article provides recommendations on key behaviors, goal setting, and quantifying impact on Instagram for extension programming. Accounts should target one niche or market, a consistent and personal voice, and regular communication (new content at least three times weekly). Unique and productive connections between extension personnel, community leaders, farmers, students, and public influencers expands programming. Tracking program accounts, including the number of followers and engagement rates, can assess program impacts and target market needs.

A cross the United States, farm demographics and the way people access information are changing. In the last Census of Agriculture from the U.S. Department of Agriculture, National Agriculture Statistic Service (USDA-NASS), the number of female farm producers increased by $27 \%$, and the number of small farms $[<10$ acres (4.0 ha) $]$ increased by $22 \%$, more than any other farm size (USDA-NASS, 2017). Of small farm producers: $44 \%$ are women, $42 \%$ have $\leq 10$ years' experience, $49 \%$ are under age 44 years ( 14 years younger than the average producer), $78 \%$ have Internet, and $40 \%$ rely on mobile-based Internet (USDA-NASS, 2017). To meet the needs of this growing group of younger, less experienced, and technologically advanced farmers, extension

Received for publication 15 July 2020. Accepted for publication 22 Aug. 2020.

Published online 25 September 2020.

${ }^{1}$ Department of Plants, Soils, \& Climate, Utah State University, 4820 Old Main Hill, Logan, UT 84322

This research was supported by the Utah Agricultural Experiment Station, Utah State University, and approved as journal paper number 9386. Additional support was provided by the USDA Risk Management Agency, Risk Management Education Partnership Program. I thank Mallika Nocco and Kynda Curtis for their friendly review of this manuscript, and Tiffany Maughan and the USU Small Farms Lab for their contributions with social media outreach.

M.S. is the corresponding author. E-mail: melanie. stock@usu.edu.

This is an open access article distributed under the CC BY-NC-ND license (https://creativecommons.org/ licenses/by-nc-nd/4.0/).

https://doi.org/10.21273/HORTTECH04693-20 programming requires modern and adaptable approaches.

Internet access and mobile devices, particularly smart phones, have increased social media networking (e.g., Poushter et al., 2018). In Utah, a rapidly growing group of predominantly new, small-scale female farmers ranked social media as the primary vehicle used to access agricultural information $(36 \%$ preference $)$ over other sources, such as Cooperative Extension fact sheets $(32 \%)$, in a survey by M.N. Stock at the Utah Urban and Small Farms Conference (survey of cut flower growers in the U.S. Intermountain West, 4 Mar. 2020). Within social media platforms, Instagram (Menlo Park, CA) was top-rated (58\%), followed by Facebook (Menlo Park, CA) $(33 \%)$, Other (6\%), and Twitter (San Francisco, CA) (3\%) by growers surveyed at the 2019 Utah Urban and Small Farms Conference by M.N. Stock (survey of cut flower growers, 20 Feb. 2019). In general, Facebook was described as an outdated platform and Twitter's format too limiting to convey useful information for farm decision-making. Indeed, outside of agriculture, Instagram is commonly known for attracting younger and more diverse groups (Salomon, 2013; Ting et al., 2015).

These trends indicate the importance of diversifying extension programming through digital applications-particularly Instagram. Cultivating an adaptive online presence allows extension to reach new clientele, promote science-based information to new farmers, and combat digital disinformation. In response, an Instagram-based extension campaign was launched to regularly share research updates, provide timely alerts for farm management, promote extension events, and, most importantly, connect with less represented farmers-namely, younger, smallscale, female growers of premium horticultural crops. The goal of this article is to l) share recommendations for key activities on Instagram and attainable goal setting, 2) discuss metrics for quantifying successes and impact, and 3 ) reflect on novel opportunities.

\section{Methods for sharing information}

Information, or content, can be shared in four interactive ways on Instagram: through posts, stories, IGLive, and IGtv. Posts are pictures or video with a descriptive caption that appear in feeds (the home page) and save to the account. They are considered relatively permanent and formal. Stories are casual-a picture or video without a caption that appears above the feed (thus likely to be seen by top followers) and disappears in $24 \mathrm{~h}$. Stories have additional features, such as polling and event countdowns. IGLive streams events for followers to engage in real time. These events can be saved and edited into short videos for IGtv, a video repository.

\section{Strategies for success}

Users decide to follow accounts that align with their interest. Therefore, developing an extension account around one niche or target market creates identity and conveys expertise in a focused area. This strategy increases followers and engagement, as opposed to content across a broad subject matter (Büscher, 2018). Timely content for the niche, such as relevant seasonal posts, are useful to farmer followers and increase engagement (see Table 1 for examples). Themed posts can also be effective for sharing extension content. For example, weekly "Fact Sheet Fridays" promote well-timed fact sheets with a fresh photo and action-oriented caption (e.g., vegetable growing guides during local planting times). Occasional posts that highlight personal experiences, feelings, and challenges 
Table 1. Types of Instagram posts and content ideas that provide useful information to engage farmer followers.

\begin{tabular}{ll}
\hline Post type & Example content \\
\hline Real-time research updates & $\begin{array}{c}\text { Small week-to-week observations or progress on field trials, new findings, or recruitment } \\
\text { for upcoming on-farm studies } \\
\text { Pest and disease identification and treatment }\end{array}$ \\
$\begin{array}{l}\text { Limest alerts } \\
\text { Outreach events }\end{array}$ & Farm planning or management considerations (tillage, fertilization) \\
& Promote upcoming events, reflect on workshops or county visits
\end{tabular}
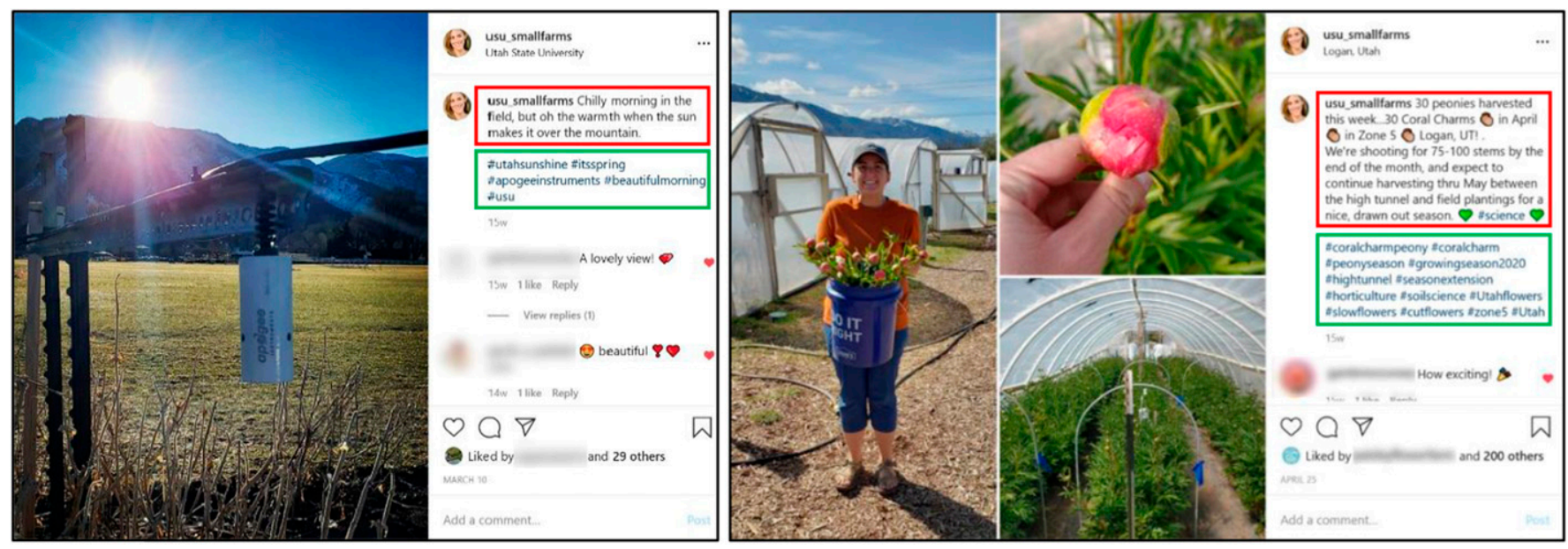

Fig. 1. Examples of lower (left) and higher (right) quality content from an extension-based Instagram account in Utah that is focused on production horticulture. Red boxes outline the captions, and green boxes outline hashtags. Although posts were in early Spring 2020, the higher quality content had an $18 \%$ engagement rate and 4 times greater reach than the lower quality content, which had a $4 \%$ engagement rate.

within the niche also boost credibility and engagement. For example, personal experiences in the home garden relate to production horticulture, provide appropriate social commentary, and reduce community barriers by showing a personal side to a professional identity. Agricultural followers appreciate a "tell it like it is" approach because this communicates honesty and humility and boosts perceived trustworthiness.

Each post builds program identity. More aesthetically pleasing content increases reach (the number of users that see a post) and engagement (how much people like, comment, share, save, and click on content). Therefore, lighting, angles, subject, and the presence of people are important considerations (Bakhshi et al., 2014). Quality captions are descriptive in a generally uplifting way, succinct, and most importantly, convey a consistent and genuine voice. Using a less institutional and more personal tone creates relatability and authenticity, key qualitative metrics that followers use to assess the validity of digital information (De Veirman et al., 2017). Lastly, including appropriate hashtags (a searchability function that uses keywords to categorize content) ensures reach. Two posts with contrasting quality illustrate these concepts (Fig. 1). The first post had a dark, less relatable picture (outside of the audience niche); a low-quality caption that was not educational or particularly genuine; and vague hashtags. The other post built program identity well. The content was a real-time research highlight and important subject matter for the audience. Presentation of this content included a collage of well-lit photographs that included a human presence; the caption had an educational, thoughtful, and personal message; and relevant hashtags were used. As a result, this post had 4 times more reach and nearly 5 times more engagement than the lower quality post.

Optimal posting frequency is debated; however, setting a goal for a consistent number of weekly posts is key to establishing expectations and maintaining reliability. Posting once per day increases account exposure, relevance, followers, and engagement (Manikonda et al., 2014). However, Ansari et al. (2019) found that most social media leaders (i.e., influencers) post up to three times per week and focus on quality. In targeting younger, female microfarmers in horticultural extension, setting a goal of three weekly posts helped maintain strong engagement rates, while providing a realistic balance between social media outreach and other academic responsibilities. Certain times of the year may present opportunities to decrease content, such as around winter holidays when engagement sharply decreases in some communities (Fig. 2).

\section{Understanding and assessing impact}

Although Instagram provides week-to-week "insights" for business accounts, archived data are limited; therefore, maintaining independent records is recommended to document impact over time (Fig. 2). 


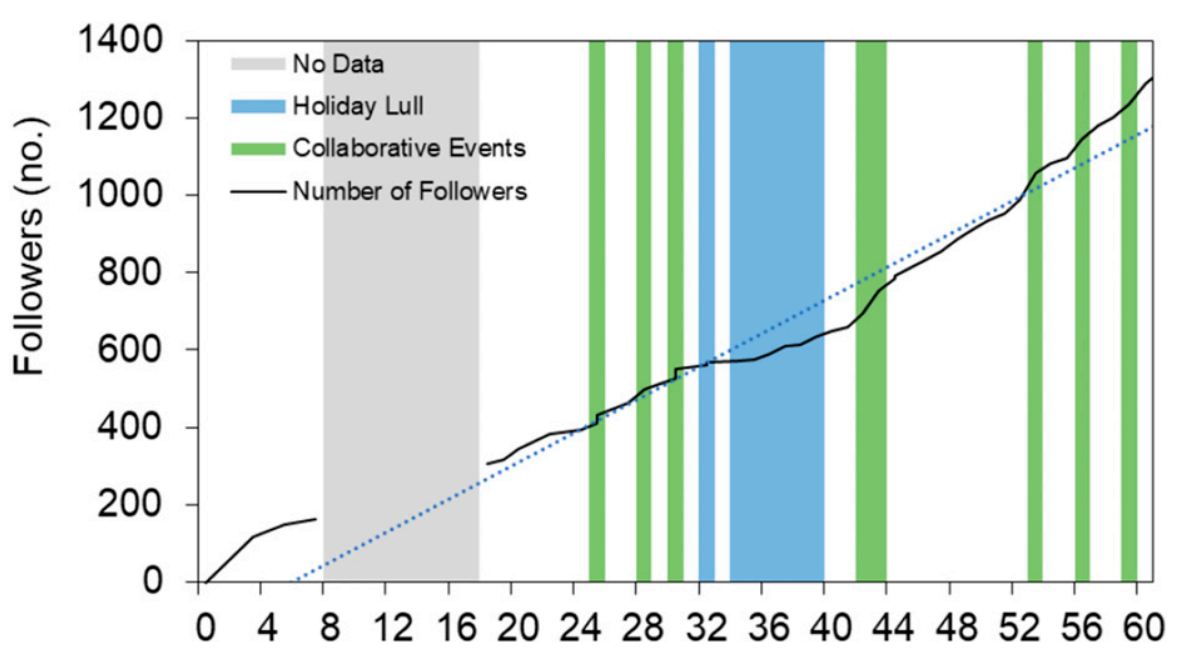

Account age (weeks)

Fig. 2. The number of followers with the age of an extension-based Instagram account that is focused on production horticulture in Utah, by week (black line). The account launched on 28 Mar. 2019 (Week 1), and data are shown through late May 2020 (Week 60). The bars denote key weeks: blue are less active periods around winter holidays, green are collaborative events with other accounts, and gray designates a gap in follower data as a lesson in independently recording account statistics.

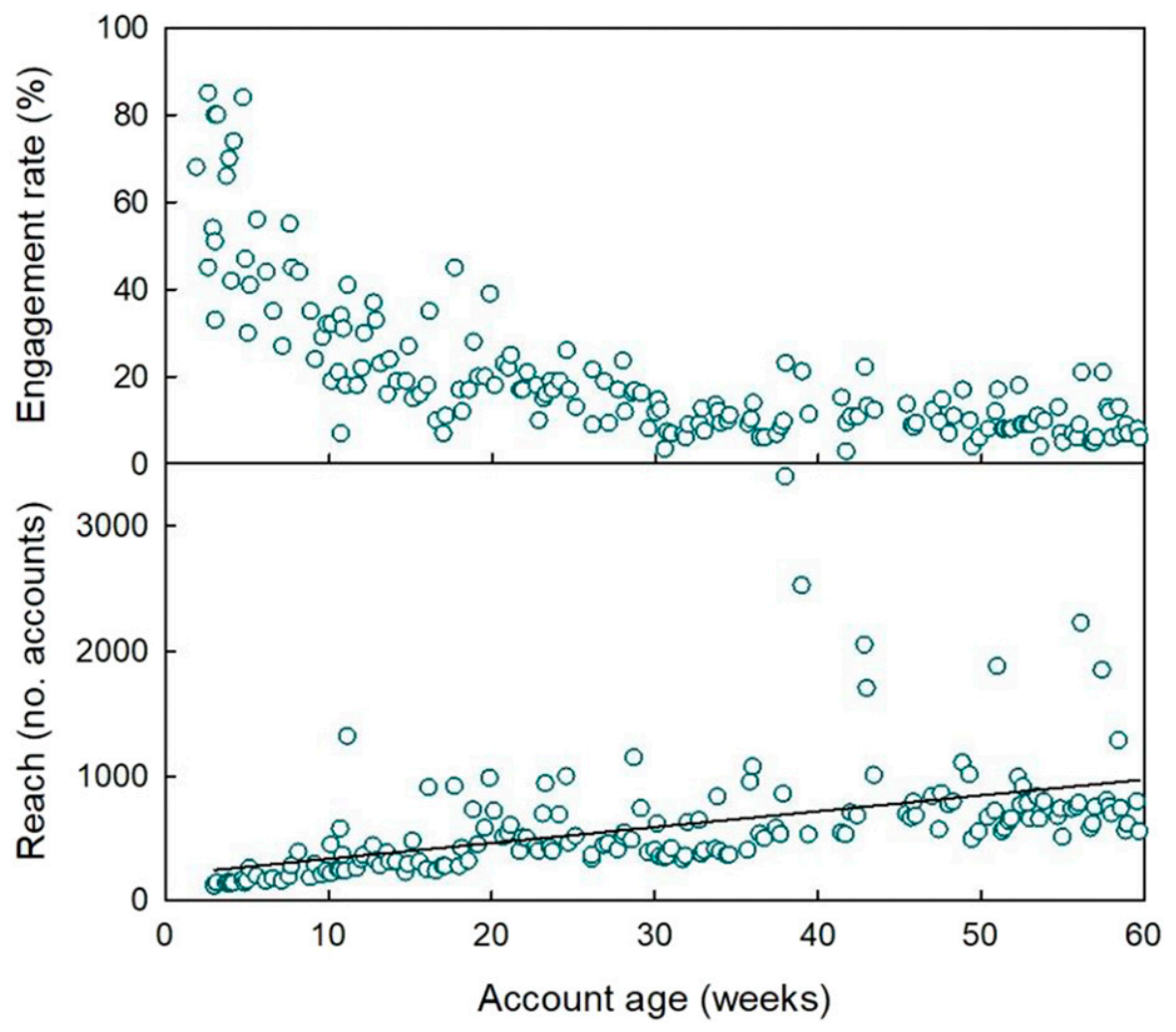

Fig. 3. Engagement rates (top) and reach (bottom) of each post from an extensionbased Instagram account that is focused on production horticulture in Utah, with account age by week. The account launched on 28 Mar. 2019 (Week 1), and data are shown through late May 2020 (Week 60).

Audience size and engagement are key metrics (Segev et al., 2018). The number of followers indicates audience size, reach, and reputation, with greater numbers indicating greater impact (De Veirman et al.,
2017). Engagement is calculated for each post or video (Ansari et al., 2019):

$$
\frac{(\text { likes }+ \text { comments })}{\text { no. followers }} \times 100
$$

Benchmarks for positive engagement rates vary, but most influencers average $3.28 \% ; \approx 5 \%$ of influencers average $10 \%$ or more (Ansari et al., 2019). Instagram-based extension programming that has a defined niche, focuses on real-time clientele needs, and has a reputation for quality content can average extremely high engagement rates. Although rates typically decrease as the number of followers increase over time, strong programs can expect to level off at $10 \%$ while increasing reach over time (Fig. 3). Both engagement and reach help quantify program impact, but engagement is generally more meaningful to convey the program's usefulness to the intended audience, whereas reach indicates the program's ability to promote content visibility.

Account content can also be categorized and ranked to create needs assessments. When preparing for an IGLive event, posts and stories may be used to poll followers for questions that can then be organized by subject matter within the niche (Fig. 4). Post captions can be used to poll followers, who reply by commenting on the post. Stories have an additional "sticker" feature, from which interactive polls can be overlaid onto a story. For example, an open-ended question or request can be created with the "questions" sticker, such as "Ask me your questions about composting"; followers reply by typing in a question on the sticker. More targeted responses can be facilitated by other types of polls, such as the "quiz" sticker. From these polls, subjects with the most questions or responses indicate greatest program need. Yearto-year changes in needs assessments on similar subject matter can also be analyzed to understand where knowledge is advancing-and where it is not.

\section{New opportunities}

Instagram-based extension programming helps reduce barriers with the public by making personnel, services, and resources less intimidating and more visible. Digital outreach 


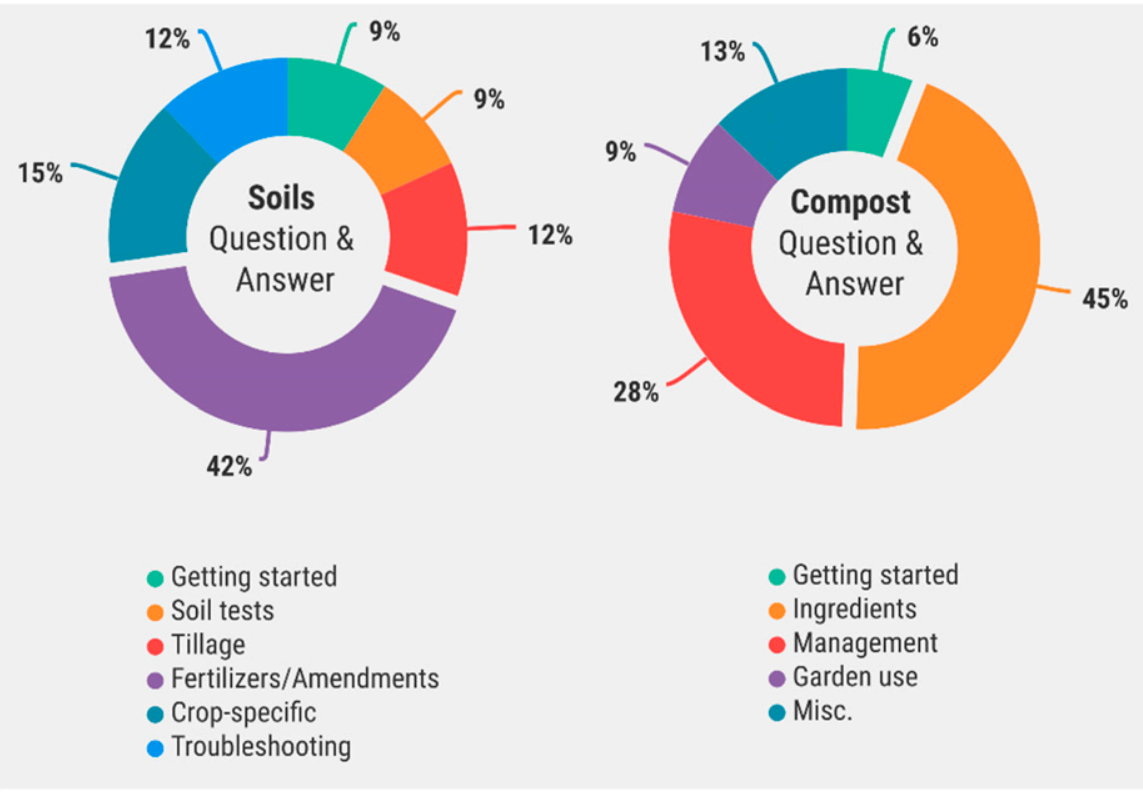

Fig. 4. Examples of needs-assessments based on polls of Instagram followers of one extension-based account that is focused on production horticulture in Utah, ahead of two IGLive events. Questions for a soil management event [ 16 Jan. 2020 (left)] received 33 questions that divided into six categories, with one category (Fertilizers /Amendments) showing greatest need. A compost event [ 27 May 2020 (right)] received 47 questions that divided into five categories, with two categories indicating strong need (Ingredients and Management). Content for the IGLive events was then tailored accordingly.
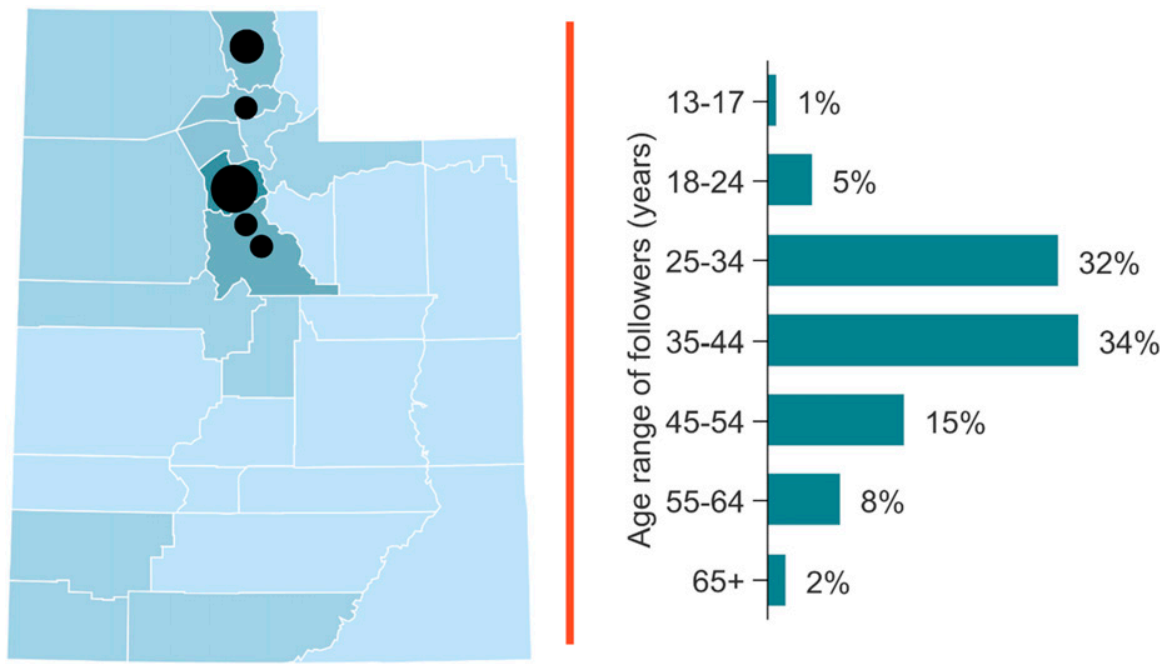

Fig. 5. Demographics of followers for one extension-based Instagram account that is focused on production horticulture in Utah. (Left) The account aimed to engage urban counties, where most women-run microfarms are located (darker shading indicates greater concentration). Overlain black circles indicate the top five cities where account followers reside because county data are not provided by Instagram (larger circles indicate greater percentages of all followers) $(n=1363)$. (Right) The age distribution across all account followers who provided age data to Instagram $(n=1322)$. Data retrieved from Instagram on 17 June 2020.

complements annual events (e.g., workshops, farm tours) by providing regular updates, contact, and information that incrementally builds knowledge without overwhelming. Moreover, maintaining a social media presence builds program flexibility for uncertain times, such as the coronavirus disease 2019 (COVID19) pandemic, when more traditional programs must pivot. To increase outreach, content can also be shared across multiple platforms by linking accounts [e.g., Instagram content can be set to simultaneously post on Facebook, Twitter, and Tumblr (New York, NY)], although editing can be needed for proper presentation on each platform. At the same time, following clientele helps inform extension on the dynamic needs across the state and adjust programming and deliverables. Crop information (e.g., crop types, varieties), the timing of farm practices, market preferences for agricultural products, and real-time challenges can all be monitored. From this, timely outreach has ranged from troubleshooting soil nutrient management-fertilizer rates of primary macronutrients or identification and treatment of iron chlorosis, to increasing the stem length and marketability of snapdragon (Antirrbinum majus) cut flowers. Instagram also helps identify new clientele and quantify program relevance to targeted groups. In the U.S. Intermountain West, Instagram has been critical to discovering the rapidly growing number of new, urban, and predominantly female-run farms (Fig. 5). Followers' demographics reflect this: $77 \%$ are women and aged 35 to 44 years are most represented, indicating appropriate digital programming.

Communication across the state can also increase. Early-career faculty can efficiently establish a voice and program and promote area expertise. Campus specialists and county extension offices can stay updated by following one another's activity. More novel connections can also be initiated that add accessibility, refresh deliverables, and spread science-based information. Extension personnel and local microinfluencers are one unique collaboration that create dynamic, relatable content. Influencers are powerful thought leaders on social media, who can serve as hosts and moderators, ensuring content is at an appropriate - and entertaining level. Collaborations rapidly grow accounts (Fig. 2) and are one of the most meaningful outcomes from social media programming.

Student engagement and training in extension is also facilitated by Instagram, furthering student awareness, 
critical thinking, communication skills, and research documentation. For example, students maintaining agricultural research trials can be tasked with 1) critically thinking about key fieldwork each week and emerging study highlights and 2 ) representing that with digital imagery and a succinct caption. This also leads to greater project investment, ability to relate day-to-day operations to broader implications, and experience communicating with wideranging audiences. Although oversight and editing are necessary to maintain a consistent program voice for followers, students often enjoy blending research with social media and have a strong intuition for digital communication.

\section{Literature cited}

Ansari, S., M.A. Tahir, and S. Bukhari. 2019. A graph-based approach for effective influencer marketing. Intl. J. Data Min. Knowl. Manag. Process. 9(4):2137.

Bakhshi, S., D.A. Shamma, and E. Gilbert. 2014. Faces engage us: Photos with faces attract more likes and comments on Instagram, p. 965-974. In: Proc. Spec. Interest Group Comput.-Human In- teraction (SIGCHI) Conf. Human Factors Comput. Syst. Assoc. Comput. Machinery, New York, NY.

Büscher, S. 2018. Critical success factors in using visual social media as social commerce platforms: The case of Instagram and Pinterest. MS Thesis, Univ. Twente, The Netherlands. 21 Aug. 2020. <http://essay.utwente.nl/75195/1/ Buescher_MA_BMS.pdf>.

De Veirman, M., V. Cauberghe, and L. Hudders. 2017. Marketing through Instagram influencers: The impact of number of followers and product divergence on brand attitude. Intl. J. Advert. 36(5):798-828.

Manikonda, L., Y. Hu, and S. Kambhampati. 2014. Analyzing user activities, demographics, social network structure and user-generated content on Instagram. Cornell Univ. Open Access Arch. 1410.8099. 1 July 2020. <https://arxiv.org/pdf/1410.8099.pdf>.

Poushter, J., C. Bishop, and H. Chwe. 2018. Social media use continues to rise in developing countries, but plateaus across developed ones. 1 July 2020. <https:// assets.pewresearch.org/wp-content/ uploads/sites/2/2018/06/15135408/ Pew-Research-Center_Global-TechSocial-Media-Use_2018.06.19.pdf>.
Salomon, D. 2013. Moving on from Facebook: Using Instagram to connect with undergraduates and engage in teaching and learning. College Res. Lib. News. 74(8):408-412. 12 June 2020. <https://crln.acrl.org/index.php/ crlnews/article/view/8991/9770>.

Segev, N., N. Avigdor, and E. Avigdor. 2018. Measuring influence on Instagram: A network-oblivious approach, p. 10091012. In: 4lst Intl. ACM SIGIR Conf. Res. Dev. Info.

Ting, H., W.W.P. Ming, E.C. de Run, and S.L.Y. Choo. 2015. Beliefs about the use of Instagram: An exploratory study. Intl. J. Bus Innov. 2(2):15-31.

U.S. Department of Agriculture, National Agriculture Statistic Service. 2017. Farm producers. 2017 Census of Agriculture highlights. 9 June 2020. <https://www. nass.usda.gov/Publications/Highlights/ 2019/2017Census_Farm_Producers. pdf $>$. 